\title{
EL COMPONENTE PRAGMÁTICO EN LOS DICCIONARIOS: IMPLICACIONES PARA LA LEXICOGRAFÍA ${ }^{1}$
}

\author{
THE PRAGMATIC COMPONENT IN DICTIONARIES: IMPLICATIONS \\ FOR LEXICOGRAPHY1
}

Julio Calvo Pérez ${ }^{2}$

\section{RESUMEN}

Los diccionarios son listados de palabras, simples o complejas, que son tratadas en lo que se conoce como artículo léxico. En este, se acostumbra a hacer valer varios componentes: el lema, nombrado en su forma más neutra, seguido de una indicación de los principales accidentes de su categoría: género y número si son nombres, clase sintáctica si son verbos. A veces se hacen indicaciones de otros aspectos: etimología, pronunciación, marcas de lugar, ámbito de empleo, registro, frecuencia de uso, etc.

Entre todo el conjunto, destaca un campo que día a día se va abriendo paso, aunque a duras penas, en las obras lexicográficas: el componente pragmático. La mayoría de las palabras son referenciales (nombres, verbos, adverbios), aunque otras se corresponden con funciones como la expresiva y la apelativa; por ejemplo, las interjecciones. Muchas palabras son objetivas, pero otras dependen de la subjetividad: como los pronombres (personales, deícticos, etc.). Además, hay categorías plenas, que no basta con ser tratadas sintácticamente (tr, intr, prnl, etc.) o semánticamente (abundanciales como bastante, discontinuativas como ya, aproximativas como casi, etc.), sino que requieren una aproximación pragmática especial, más allá de sus usos neutros: prometer es voz asertiva o comisiva, gracias es expresiva, ah es fática, posible es modal, etc.

Pues bien, conceptualizar tales hechos es lo que trata de incentivar este artículo, con la convicción de que todas las palabras del lenguaje están en función de sus usuarios en un contexto dado, campo indudable de la Pragmática.

\section{Palabras clave}

Lexicografía, componente pragmático, funciones del lenguaje, actos de habla, verbos perlocutivos

\section{ABSTRACT}

Dictionaries are a list of words, simple or complex, that are treated as entries (lexical items). It is usual to assert several components: the lemma or headword, named after its most neutral form, followed by an indication of the main inflections of its category: genre and number if they are

Este trabajo se presentó como ponencia al VII Congreso Internacional de Lexicología y Lexicografía de la Academia Peruana de la Lengua en homenaje a Luis Jaime Cisneros Vizquerra, que tuvo lugar los días 4, 5 y 6 de octubre de 2012, permaneciendo inédito hasta el presente.

2 Es Catedrático jubilado de Língüística General de la Univeridad de Valencia (España). Ha publicado más de 30 libros y superado los 120 artículos de especialidad y capítulos de libros, habiendo sido el creador de la teoría de los espines (La fundación de la Semántica: los espines léxicos como un universal del lenguaje. Madrid, Iberoamericana-Vervuert, 2011). Dirige la UniverSOS, Revista de Lenguas indígenas y universos culturales, que va por su número 11. 
names, syntactic class if they are verbs. Sometimes, indications of it are made in other aspects: etymology, pronunciation, marks of placement, area of use, register, frequency of use, etc.

Among all the group, it is pointed out an area that grows daily, painstakingly, in lexicographic works: the pragmatic component.

Most of the words are referential (names, verbs, adverbs), but others correspond to language functions like the expressive and appellative ones; for example, interjections. Many words are objective, but some others depend on subjectivity, such as pronouns (personal, deictic, etc.), furthermore, there are complete categories that cannot be tackled with a syntactical approach only (tr., intr., pron., etc.) or semantically (meaning number like many, meaning an interruption like no longer, meaning approximation like almost, etc.), rather, they need to be studied within the framework of a special pragmatic approach, beyond their neutral uses--so to promise forms part of an assertive or commissive

Advances arise from cultural, social, economic, political and historical moments of the society in general. Furthermore, the authors that posed the concept of cultural industries do not belong to this century (21st century) which is why they have not witnessed the systematic and progressive advances of industries (creative and content).

\section{Keywords}

Cultural industries, creative industries, content industries

Son varios los pilares en los que se fundamenta un diccionario. Los podemos recordar sucintamente: una planificación general de la obra, su desarrollo en macro y microestructuras y una modulación variable que proporciona los mecanismos para su estructuración. Finalmente, se requiere de una técnica depurada que permita armonizar el conjunto y dar solución al puzle presentado: definición, ejemplos, etc. para completar el desarrollo y facilitar su encaje.

Si nos atenemos a la modulación, esta consta de una serie de componentes bien conocidos, que no siempre se presentan total o parcialmente. Estos pueden ser la ortografía, la etimología, la gramática, la sociolingüística, la semántica, la geografía lingüística, la adscripción científica y la marca de uso. El más importante de todos ellos es el semántico. El proyecto DiPerú, que dirijo (2008-2012, ambos inclusive), ha procurado incorporar todos y cada uno de esos factores, además de ejemplos y de redes.

\section{EJEMPLOS:}

caviar: Etimología: < fr. gauche caviar, $\mathrm{c}^{*}$ con izquierda] caviar $<$ it. ant. caviaro $<$ turco hāviâr 'huevas de esturión' ('izquierda política acomodada' / Marca gramatical: com. / Marcas sociolingüísticas: desp. / Definición: Miembro de la izquierda política, que procede de una familia de posición socioeconómica acomodada. / CC.SS.: izquierda caviar, rábano. / Derivados: caviarada, caviaraje.

tira: Etimología: < tirante, con apóc. / Marca gramatical: m. / Marcas sociolingüísticas: coloq. / Marcas de frecuencia: p.us. / Definición: Policía no uniformado, cuyo trabajo es fundamentalmente de investigación. / Ejemplo: Hasta la Panamericana, no paró de hablar, como siempre: sus quince años en el cuerpo. Y no como un simple tira, Ludovico, sino dentro del escalafón, y de los hampones que le habían jodido la pata a chavetazos esa vez. ${ }^{1}$ / Referencia bibliográfica: Vargas Llosa, Mario. Conversación en La Catedral. Barcelona: Seix Barral, 1969. p. 313. / CC. SS.: tombo.

yacumama: Etimología:< q. yaku 'agua' + mama 'animal grande, madre' / Marca gramatical: f. / Marcas diatópicas: OR. / 
Definición: Boa de color verde oscuro... N. c.: Eunectes murinus. ${ }^{3}$

Pero hay un componente no citado explícitamente todavía: el llamado componente pragmático. ${ }^{4}$ La descripción del uso, no en cuanto a su frecuencia sino en cuanto a las funciones del lenguaje que entran en juego, tiene que ver muy íntimamente con la sociolingüística, hasta el extremo de que para muchos son indisociables. En la praxis diaria de DiPerú, se ha incorporado también en el mismo nivel que el componente sociolingüístico, aunque es preciso señalar que no deben confundirse, aunque se incluyan a la par: la razón está en que es preciso evitar cualquier extrañamiento, lo que es letal para el reconocimiento social del diccionario.

La sociología se encarga de señalar si una palabra es culta o vulgar, popular o urbana, formal o festiva; si es un eufemismo o un disfemismo, un tabú o una palabra vejatoria. ${ }^{5}$ La pragmática, en cambio, se encarga de la determinación del Emisor y del Receptor, de los actos que ambos suscitan y de la situación en que se producen. Por este hecho, la pragmática está llamada a ocupar todo el espectro léxico, pues ninguna palabra es ajena a esa puesta en común. En esto concuerda con la sociolingüística, aunque esta representa un mundo de más amplia ejecución y es más externa; la pragmática, por su parte, hace de frontera entre la gramática y el mundo externo que representa la sociolingüística, compartiendo rasgos con los dos.

Imbricada en el lugar señalado, la pragmática tendrá la amplitud que queramos darle. Una pragmática como la de Calvo (1985, 1993, 1994), en el ámbito de la Lingüística liminar, abarca todo el léxico. Otras propuestas se circunscriben a elementos directamente sensibles a la ubicación de los actores del habla (deícticos), a la referencia de los mismos y los objetos materiales o inmateriales en general (artículo y pronombres), a la modalidad (modo real e irreal), a la temporalidad (presente, pasado o futuro), a la actitud del hablante o la evidencialidad (Benveniste 1978, 1983). La pragmática estadounidense prefiere incidir directamente en aspectos sociales como es el desarrollo de los mecanismos de las relaciones humanas a través del lenguaje: máximas, cortesía, relevancia (Grice 1989a y b, Leech 1983, Sperber y Wilson 1994).

La pragmática inglesa (Austin [1962] 1982), anterior a ella, se fija sobre todo en la calidad de los actos de habla y en cómo hacer cosas con palabras, lo que se llama la performatividad. Es apenas un breve resumen de lo que esta disciplina nos enseña, sobre todo desde que Brown y Levinson (1987), Récanati (1982) y otros muchos autores, ya en rigor clásico, ya como divulgadores (Reyes 1990, 1995), la han desplegado en estos términos.

Se cuentan por decenas de miles las publicaciones respecto a la pragmática desde el último cuarto de siglo pasado hasta hoy. Calvo $(1993,1994)$ ha desarrollado, a su vez, el grado de incorporación categorial de la pragmática hasta alcanzar meollo de la gramática (la Morfosintaxis), que ya escapa de las preocupaciones nucleares del diccionario, aunque haya autores que la colocan como axial en el sistema: teoría distribucional o formal de Vendler (1967) o Apresjan (2000), Esquemas sintáctico-semánticos (Báez 2002), Diccionario combinatorio (Mel'čuk et al. 1984), etc.

\footnotetext{
3 De los componentes citados ha quedado escindido en el proyecto DiPerú el de la ortografía (septiembre 2011), por acuerdo general de sus componentes. Por tanto, la Academia ha de procurar en el futuro rellenar el hueco creado. Por acuerdo también se modifica el criterio de definiciones, introduciendo las impropias y permitiendo, además, que el definiendum penetre en el definiens, al estilo de lo que propugna la RAE, sin duda como consecuencia de una visión periclitada de la lexicografía (septiembre 2012).

4 Tampoco DiPerú es propenso a admitir el componente que explicitamos aquí (septiembre 2012), lo que no le quita valor intrínseco a la propuesta, dado que los avances sobre este componente, en la lexicografía moderna, tienen valor por sí mismos como se aprecia en las líneas que siguen.

5 Tampoco es ajena a las preocupaciones sociológicas la ortografía, verdadera piedra de toque de todo diccionario normativo, aunque la sociedad suele ser siempre muy conservadora al respecto de hábitos pasados, al tiempo que es permisiva para aceptar la libertad individual hasta términos escandalosos, lo que sin duda está sucediendo en Internet.
} 
Pero la lexicografía, disciplina difícil donde las haya, ha sido renuente a incorporar estos avances en su seno. Es una especialidad siempre a remolque de los desarrollos punteros de la teoría del lenguaje, quizá como tantas otras ciencias aplicadas, que son absorbentes de los inventos especulativos y al mismo tiempo un lastre displicente que los pone constantemente en duda. En esa tesitura y para romper con el maleficio, DiPerú no puede ni debe estar ajeno a una serie de elementos léxicos que constituyen la nómina de las categorías pragmáticas, pues de otro modo se vería ante arduas dificultades para incorporar el léxico diferencial del idioma, que es su objetivo. Como no hay probablemente mucho tiempo para desarrollar en profundidad los múltiples aportes de la Pragmática vamos a comentar los más evidentes.

Uno de ellos es que toda palabra o locución, a mi modo de ver, tiene una marca pragmática. Lo que llamé Pragmática Léxica (Calvo 1985). Todas las palabras se adscriben a una o más funciones del lenguaje, si recordamos a Bühler ([1934] 1950) y Jakobson (1963), pues pueden hallarse en múltiples textos y bajo diversas intenciones. Del mismo modo que todas las palabras o locuciones son proclives a un determinado registro. Tanto si una palabra es usual, común y fundamental en un idioma (García Hoz 1953), como si no lo es, debe adscribirse a un registro: será estándar, en cuyo caso no se señala en el diccionario, o quizá culta, festiva, vulgar, popular o coloquial, siendo entonces marcada convenientemente en el artículo léxico.

Lo mismo sucede con el componente pragmático o sociopragmático: cualquier entrada léxica es ref. (referencial) por defecto; quiero decir que al igual que el registro estándar la función referencial no se indica, sino se adjudica como fondo de las palabras y actos, por no marcada. Palabras como alfajor, chamba o yacón en principio no se categorizan. Pero las funciones del lenguaje no son simplemente las comunicativas: hay elementos de contacto o fáticos (fát.), hay palabras y expresiones que solo tienen sentido desde la función expresiva (expr.) del Emisor o de la apelativa (apel.) del Receptor, aunque sean las menos, y entonces deben señalarse: mamacita debe marcarse, lo mismo que cholo en una de sus acepciones, cuando es " $<$ Forma de tratamiento afectuoso $>$, equivalente a iCariño! iAmor! iMi amor!", como recoge finamente $\mathrm{P}$. Negrini en el ejemplo siguiente de DiPerú: Medio ahogada en sollozos, repetía con infinita lástima: Hijito, cholito, amor mío, qué te han hecho. Qué ha hecho contigo esa mujer. Lo mismo valdría para guanaco, cuando se emplea vocativamente como insulto: ¿Qué estupideces dices, guanaco, tonto? o bien así como viejo / vieja que tiene su marca expr. (expresivo): "<Generalmente usado como apelativo> Padre o madre". En otros casos la fuerza es más bien apelativa: como en chuspi: " $<$ Referido a una persona $>$. fig. iAtento! iAlerta!": -Mira que han llegado más pasajeros. Apúrate con los platos. !Chuspi, chuspi! !Ponte chuspi!", ejemplifica María Chavarría. ${ }^{6}$

La interjección y el vocativo. El vocativo se ha discutido siempre desde el latín sobre su estatuto de caso. No es realmente un caso puesto que su marbete no alude a una etiqueta de rol sintáctico: no es sujeto ni objeto, no es complemento del nombre, no indica circunstancia de lugar o tiempo. El vocativo es un caso propio de la función apelativa, es un recurso eminentemente pragmático que no debe contemplarse en el conjunto de los casos; de hecho muchas veces no se marca o lo hace esporádicamente (-e: Salvē, alumnule). Se podrá ver en los ejemplos anteriores, que van entre comas. Lo mismo sucede con la interjección: no es una categoría al uso. Cuando se añadió en la gramática de Prisciano al listado junto con el verbo, el participio, el nombre, fue para completar un paradigma donde el onoma, el rema y syndesmos copaban las descripciones categoriales. La interjección no es rol estructural de ninguna inserción léxica en la frase, no significa en sí nada (si

Augusto Alcocer (en comunicación personal) considera que el habla habitual limeña chuspi es sustituido por mosca, con igual sentido pragmático. De hecho, chuspi funciona como calco o traducción del quechua al castellano, en aquellos lugares como la Amazonía en que la lengua andina ha dejado huella indeleble. 
es pura). Muestra apelativa o expresivamente el mundo, señalando reacciones $\mathrm{o}$ entes referenciales, pero exentas de sentido locutivo. $\mathrm{Su}$ fuerza es ilocutiva, sobre todo en las interjecciones propias, que no se analizan en los diccionarios ni pueden definirse tampoco; en cambio las impropias o secundarias tienen un estatuto locutivo mínimo, a expensas directas del contexto como señalan los autores (Ameka 1992, Wierzbicka 1992, Calvo 1997). ¿Hemos de quitarlas del diccionario? No tal. Hemos de definirlas referencialmente. No tal. Les señalaremos el contorno de su uso y, a ser posible, o cuando sea viable, les daremos una equivalencia asequible, igualmente expresiva o apelativa: es lo que hacen los traductores y lo que se observa en los diccionarios bilingües cuando no hay una equivalencia directa en otra lengua. ${ }^{7} \mathrm{Y}$ ello es posible, conforme se asegura, aunque mayoritariamente los lexicógrafos del español han rehuido hacerlo: les resulta más cómodo dar una aproximación explicativa, metalingüística, casi siempre impresiva y sin un corpus lo suficientemente completo que permita verlas en toda su magnífica dispersión (Fábregas y Gil 2008).

No obstante, una palabra como Salve puede definirse como iTe saludo!, en el mismo orden expresivo en que se mueve, el ilocucional. Por cierto, que este es un "invento" peruano. Ha sido Lira (1944) y otros lexicógrafos andinos quienes han dado las equivalencias en sus vocabularios o diccionarios bilingües: alalay! 'iQué frío!, achachao! 'iQué dolor!'. 2. iQué calor!', etc., los cuales, al integrarse como préstamos al castellano tienen ya de inmediato la misma equivalencia traductológica que la necesidad les prestó. ${ }^{8}$ Debe ponerse en este caso el registro pragmático, el contexto habitual del uso, que suelen ser varios y al final una equivalencia aproximada, general, que recoja al menos la emoción que el Emisor evoca:
'Alegría!', ‘iEsperanza!', 'iSorpresa!', sería en algún caso las equivalencias útiles para la definición de esta categoría.

Las definiciones impropias, a mi juicio y al juicio de otros muchos lexicógrafos, suponen la máxima frustración en el afán de definir propiamente cualquier entrada del diccionario; por eso se ha de investigar en esta línea hasta llegar a una solución y, hoy más que nunca, esta parece avistarse en el componente pragmático. Yo diría que únicamente las interjecciones propias, los determinantes y ya claramente los sufijos y en la mayoría de los casos los prefijos, deben definirse impropiamente, ya que no tienen independencia semántica, es decir, dejando solamente el contorno. Aun así, ha de valorarse de alguna manera la epifanía semántica de su papel en la palabra. En resumidas cuentas, la interjección es palabra independiente, como el vocativo, incluso más independientes que cualquier otra categoría léxica, puesto que funcionan solas, entre comas, con valor propio $y$ riqueza incomparables.

Este quizá no sea el lugar para explorar a fondo tan apasionantes temas, pero querría dedicar todavía una aproximación a tres conjuntos de verbos. Son verbos generales del español; de ahí que no quepan por lo regular en un Diccionario de peruanismos: me refiero a los verbos modales, a los implicativos y a los performativos. Los verbos modales, que a veces operan como adjetivos o sustantivos de modalidad, son aquellos como deber, querer, poder o ser posible, ser probable, ser capaz, ser obligatorio, etc. que indican si estamos ante una modalidad alética (lo necesario / lo imposible...), epistémica (lo probable / lo posible...), deóntica (lo debido / lo prohibido...), dinámica (lo capaz / lo incapaz...) o bulímica (lo querido / lo

Véase un ejemplo de la traducción entre polaco y español en http://romdoc.amu.edu.pl/kudelko.html, reg. 30 septiembre 2012.

8 No hace mucho, en un vocabulario culle, recogido por Flores Reyna, Manuel: "Recopilación léxica preliminar de la lengua culle" En Tipshe (Revista de la Facultad de Humanidades de la Universidad Nacional Federico Villarreal), Lima, 2000: 173197, leíamos ejemplos como "cuta: ibasta!, idescanso un rato! <en los juegos>", "queshque: dicen que, iqué va a ser!" y otros. En la misma ponencia de cierre del VII Congreso Internacional de Lexicología y Lexicografía en homenaje a Luis Jaime Cisneros Vizquerra (Lima 4-6 octubre 2012), que tuve el gusto de compartir con la Dra. y académica costarricense Estrella Cartín de Guier, esta señaló cómo achará en el castellano de su país equivalía a 'iqué lástima!' Con ello vemos cómo la costumbre de aceptar las equivalencias pragmáticas como tales se está extendiendo por toda Latinoamérica. 
rechazado), indicando la manera de abordar los hablantes el contenido de sus mensajes. Obsérvese que un verbo como poder funciona de modo diferente en María puede venir (<es posible que venga $>$ ), María puede comprar pisco (<le está permitido que lo haga $>$ ) o María puede hablar (<tiene facultades físicas para ello>). Estos aspectos deben reseñarse como distintas acepciones del verbo poder para lo cual se han de explayar con claridad en la Planta lexicográfica las distintas maneras de materializar las modalidades de una lengua o de determinado dialecto.

Pasamos ahora a los verbos implicativos. Todo verbo encierra presuposición de $<$ ser $>$, a falta de otra: Si un ecuatoriano lo hizo, ella también puede hacerlo, implica la existencia de ambos. En estos casos, que son los generales, el diccionario no introduce ninguna marca. Pero hay otros verbos que requieren de explicaciones más allá de la factividad: por ejemplo el verbo evitar. Si decimos Juan evitó un accidente, es que <Juan no se accidentó $>$ y entonces hay que indicar de algún modo la contrafactividad (contrafact.), como cuando se dice Si tú hubieras estado / habrías estado aquí, las cosas serían de otro modo, que señala que alguien no estuvo (Kiparsky y Kiparsky 1970), pero ya revierte a la modalidad gramatical directamente y no al diccionario. El verbo creer tiene una lectura de cada tipo: ¿Es que no me crees? ('Dar asenso, apoyo o confianza a alguien') no funciona igual que Juan cree que Londres es la capital de Inglaterra tan verdadera como Juan cree que Londres es la capital de Francia, puesto que creer es verbo no factivo (no fact.). En Juan cree que su padre se fue se presupone tanto <Juan se ha ido $>$ como < Juan no se ha ido > . Karttunen (1971) clasificó estos verbos de una manera sorprendente a la que no aludiré aquí sino de pasada. Fíjense que si digo Juan no evitó el accidente, es que el accidente se produjo (fact.). Obsérvese que si digo Juan lamentó que María se fuera o si digo Juan no lamentó que María se fuera es que ambos casos <María se fue $>$. Aquí el estatuto no es el mismo de evitar o el de un verbo existencial como ir o no factivo como creer, por lo que a la presuposición o implicación se refiere. ¿Y el verbo intentar? Si digo Juan intentó irse es que se < Juan se fue o no se fue $>$, pero si digo Juan no intentó irse es que <Juan no se fue $>$, lo cual nos lleva a otra subcategoría. Con obligar tendríamos a su vez una nueva tipología: $\mathrm{Si}$ digo El padre obligó a su hijo a quedarse, es que <el hijo se quedó>, pero si niego con $E l$ padre no obligó a su hijo a quedarse, entonces $<$ el hijo se quedó o no se quedó>, cayendo de nuevo en ambigüedad presuposicional, ahora con el negativo. Resumiendo lo dicho y completando la información que falta, tendríamos los siguientes tipos de verbos:

\begin{tabular}{|c|c|c|c|c|}
\hline CLASE & O.M & O.C. ${ }^{9}$ & VERBO & ESTRUCTURA LÓGICA \\
\hline factivos & $+/-$ & + & lamentar... & Si $\mathrm{p} /-\mathrm{p} \rightarrow \mathrm{q}$ \\
\hline implicativos & a & a & conseguir... & Si $\mathrm{p} \rightarrow \mathrm{q}$ \\
\hline implicativos NEG & $\mathrm{a}$ & $-\mathrm{a}$ & evitar... & Si $p \rightarrow-q$ \\
\hline verbos SI & + & + & forzar... & $\mathrm{Si} p \rightarrow \mathrm{q}, \mathrm{si}-\mathrm{p} \rightarrow \mathrm{q} /-\mathrm{q}$ \\
\hline verbos SI NEG & + & - & impedir... & Si $\mathrm{p} \rightarrow-\mathrm{q}, \mathrm{si}-\mathrm{p} \rightarrow \mathrm{q} /-\mathrm{q}$ \\
\hline verbos SOLO SI & - & - & tener la oportunidad de... & $\mathrm{Si}-\mathrm{p} \rightarrow-\mathrm{q}$, si $\mathrm{p} \rightarrow \mathrm{q} /-\mathrm{q}$ \\
\hline verbos SOLO SI NEG & - & + & dudar & $\mathrm{Si}-\mathrm{p} \rightarrow \mathrm{q}$, si $\mathrm{p} \rightarrow \mathrm{q} /-\mathrm{q}$ \\
\hline
\end{tabular}

O.M. es oración modal (modus) y O.C. oración de contenido proposicional (dictum). 
Obsérvese por ejemplo que un verbo como poder (al igual que tener la oportunidad de) se adscribiría a la clase de verbos SOLO SI: Si decimos Juan no pudo abandonar el país, entonces <Juan no se fue $>$, pero si decimos Juan pudo abandonar el país, entonces < Juan se fue o no se fue>, etc. Ustedes dirán que eso es muy complicado para el consultor de un diccionario. Puede ser, salvo que en un diccionario bilingüe un verbo funcione de manera diferente en la lengua de llegada; la traducción al inglés de arreglárselas, por ejemplo, implica dos cosas, por eso que se traduce tanto por get by como por get by on: No es lo mismo Aunque no habla shipibo se las arregla (= apaña) como puede que Ella puede arreglárselas (= pasa) solo con agua y arroz. ¿Que quizá no deban estar esas referencias en el diccionario? Pues bien, es posible que no figuren por las dificultades para interpretarlas. Es como cuando escribimos solamente intr. (intransitivo), aunque debiéramos diferenciar en el conjunto total dos subclases sintácticas: los verbos inacusativos y los verbos inergativos en una nueva versión lexicográfica que los acoja: No es lo mismo la intransitividad de Juan trabaja duro, Mi madre llora a menudo, El perro ladra (verbos inergativos en que Juan, mi madre y el perro son agentes) que la de $\mathrm{Ha}$ salido el sol, Faltan dos muchachas, Va a hervir el agua (verbos inacusativos en que el sol, dos muchachas, el agua son metas).

He puesto una vela al diablo complicando voluntariamente las cosas. Pero digo en cambio que no deben faltar otras referencias: las de los verbos performativos. En mi país hay dos verbos prometer: uno que exige futuro como condición de éxito (felicity conditions, Searle 1969), al igual que una advertencia o una amenaza en Te prometo que haré las tareas después, que podríamos llamar prometer ${ }^{1}$; y otro, al que podríamos llamar prometer ${ }^{2}$ que se presenta en pasado: Papá, te prometo que ya hice las tareas del cole. En este caso, es obligatorio indicar que hay dos verbos diferentes, uno con la marca com. (comisivo), que significa 'dar palabra' proyectado a un cumplimiento posterior, y otro con la marca asert. (asertivo), que significa 'asegurar' sobre un cumplimiento anterior. Así, resulta que tenemos varios verbos asertivos (decir, contestar, argüir, postular, afirmar, negar, informar, responder, replicar, avisar, deducir, interpretar, definir... y prometer $^{2}$ ) y varios verbos compromisivos o comisivos (prometer ${ }^{1}$, garantizar, apostar...).

Un verbo como decir puede ser también de este segundo tipo: Te digo que iré. Y jurar lo mismo: Te juro que lo haré. No obstante jurar en su uso habitual es 'hacer un juramento' y entonces se comporta como decl. (declarativo), lo mismo que bautizar, jurar, condenar -dicho por un juez al final de una sentencia (Puedo condenar y condeno)-, abrir y cerrar la sesión, clausurar - (Doy por clausurado este congreso) -, inaugurar, bendecir, maldecir, declarar la guerra... En este último caso "decir" es "hacer" (Austin [1962] 1982).

Los verbos directivos implican el registro apel. (designar, ordenar, instar, aconsejar, prevenir, perdonar, rogar, suplicar; revocar, rechazar, vetar) y los verbos expresivos el rasgo expr. (felicitar, dar el pésame, elogiar, brindar, pedir disculpas, desear suerte o dar la bienvenida). No puedo ni debo extenderme aquí, pero de los verbos declarativos hay una larga lista de diferencias según los matices aportados (Bach y Harnisch 1979): asertivos (afirmar, negar, declarar), predictivos (predecir), retractativos (abjurar), informativos (informar), adscriptivos (atribuir), confirmativos (ratificar, verificar, decidir), supositivos (suponer), conformativos (aceptar) y disconformativos (rechazar), disputativos (objetar), concesivos (reconocer), replicativos (responder) y sugestivos (sugerir), todos los cuales tienen como verbo abierto o genérico el verbo decir. ${ }^{10}$ Son conocimientos que se tendrán a la hora de definir, pero que no es preciso marcar salvo con el rasgo asert.: asertivo, que es general y se adjudica a todos ellos. Y otra cosa: estos verbos tienen vigencia

10 Hay muchos verbos que sin ser propiamente asertivos pueden funcionar como tales en determinados contextos. Por ejemplo en -Hemos tenido un día menos de descanso que nuestro adversario y no ha habido tiempo material de preparar el partido-, soltó el entranador (soltar es aquí un verbo asert. enfático, de carácter aspectual imprevisivo). Esto es norma general que se aplica a muchas otras palabras en que el sentido pragmático obliga a considerar nuevas acepciones. 
solamente en primera persona de indicativo, por lo que no deben sobrepasar el campo de las "Anotaciones" en el nivel que corresponda, o en usos de cita directa como en el ejemplo de la nota 9. Los adverbios de afirmación, negación y duda, pertenecen también a este tipo, pero con diferencias: no es lo mismo sí que también o no que tampoco. En este caso, también es un adverbio asertivo afirmativo confirmativo, lo contrario que tampoco, que es negativo desconfirmativo, y que también indican subyacentemente algún estado de cosas.

Hay otros muchos verbos que implican al Emisor y al Receptor. Por ejemplo agradecer y disculpar, que implican acción invertida $(\leftarrow \mathrm{R}$ $\mathrm{y} \rightarrow \mathrm{R})$ y signo invertido $(+/-)$, lo que daría pie a mejores clasificaciones. Fíjense lo lejos que quedaría la clasificación semántica de Verschueren (1980), que siendo pragmatista no tiene en cuenta estos parámetros léxicos. Estas referencias se utilizarán solo cuando haga falta, para no hacer el diccionario más barroco de la cuenta. Pero serán obligadas en casos de vocativos e interjecciones, pues por ellas se vehiculan los significados ilocutivos que las palabras o locuciones de este tipo promueven. Será necesario marcar también algunos pronombres (deícticos) y los determinantes. Y esto no es nuevo: por lo menos desde Bühler ([1934] 1950), los lingüistas se las han venido tomando poco a poco cada vez más en serio.

Gracias, que por cierto es palabra expresiva. 


\section{REFERENCIAS}

Ameka, Felix K. (1992a) Interjections: the universal yet neglected part of speech, en Journal of Pragmatics N. ${ }^{\circ} 18,101-118$.

Ameka, Felix K. (1992b) The meaning of phatic and conative interjections, en Journal of Pragmatics N. ${ }^{\circ} 18,245-271$.

Apresjan, Juri (2000) Systematic lexicography. Oxford: Oxford University.

Austin, John L. (1982) How to Do Things with Words. The William James Lectures delivered at Harvard University in 1955. Oxford: Clarendon, Ed. James O. Urmson, 1962. Traducido por Genaro R. Carrió y Eduardo A. Rabossi: Cómo hacer cosas con palabras: Palabras y acciones. Barcelona: Paidós.

Bach, Kent y Robert M. Harnisch (1979) Linguistic communication and speech acts. Cambridge, The MIT Press.

Báez San José, Valerio (2002) Desde el hablar a la lengua. Prolegómenos a una teoría de la sintaxis y la semántica textual y oracional. Málaga, Ágora.

Benveniste, Emile (1978 y 1983) Problemas de lingüística general I y II. México: Siglo Veintiuno.

Brown, Penelope y Steven Levinson (1987) Politeness. Some Universals in Language Use. Cambridge: Cambridge University Press.

Bühler, Karl (1950) Sprachtheorie. Die Darstellungsfunktion der Sprache Jena, Fischer, 1934. Traducido a español por Julián Marías: Teoría del lenguaje. Madrid: Revista de Occidente.

Calvo Pérez, Julio (1985) Clasificación Semántica de los adjetivos puros del español contemporáneo. Valencia: Universidad de Valencia.

Calvo Pérez, Julio (1993) Pragmática y gramática del quechua cuzqueño. Cuzco: CERA Bartolomé de las Casas.

Calvo Pérez, Julio (1994) Introducción a la Pragmática del español. Madrid: Cátedra.

Calvo Pérez, Julio (1997) “iiInterjecciones!!”. Enrique Serra Alegre et al. (eds.): Actes del $1^{\text {er }}$ Congrés de Lingüística General, Vol. III. Universitat de València, 85-98.

Fábregas, Antonio y Gil Laforga, Irene (2012) "Algunos problemas de la interjección en lexicografía". R(afael). Monroy y A(quilino) Sánchez (eds.): Actas del XXV Congreso Internacional de AESLA. Murcia: Universidad de Murcia, 2008. 631-638. En http://tinyurl.com/9eyzhaw, reg. 30 septiembre

García-Hoz, Víctor (1953) Vocabulario usual, vocabulario común y vocabulario fundamental: (determinación y análisis de sus factores). Madrid: Consejo Superior de Investigaciones Científicas.

Grice, Herbert P. (1975) "Logic and Conversation". Peter Cole and Jerry L. Morgan (eds.): Syntax and Semantics, vol.3: Speech acts. New York, Academic Press, pp. 41-58. 
Grice, Herbert P. (1978) "Further Notes on Logic and Conversation". Peter Cole (ed.): Syntax and Semantics, vol. 9 New York, Academic Press, pp. 113-127.

Jakobson, Roman (1963) Essais de linguistique générale. París, Éditions de Minuit.

Karttunen, Lauri (1971) "Implicative verbs". Language 47, 2, pp. 340-358.

Kiparsky, Paul y Carol Kiparsky (1970) "Fact". Manfred Bierwisch and Karl E. Heidolph (eds): Progress in Linguistics. The Hague: Mouton, pp. 143-173.

Leech, Geoffrey N. (1983) Principles of Pragmatics. London, Longman.

Lira, Jorge A. (1944) Diccionario kkechuwa-español. Tucumán, Univ. Nacional de Tucumán: Instituto de Hist., Ling. y Folk. Pub. n 12.

Mel'čuk, Igor A., con la colaboración de Nadia Arbatchewsky-Jumarie, Lidija Iordanskaja y Adèle Lessard et al. (1984) Dictionnaire explicatif et combinatoire du français contemporain: Recherches lexico-sémantiques I, Montréal: Presses de l'Université de Montréal.

Récanati, François (1982) Les énoncés performatifs. Paris, Ed. de Minuit.

Reyes, Graciela (1990) La pragmática lingüística. Barcelona: Montesinos.

Reyes, Graciela (1995) El abecé de la pragmática. Madrid: Arco Libros.

Searle, John (1969) Speech Acts. An Essay in the Philosophy of Language. Cambridge, Cambridge University Press.

Sperber, Dan y Deirdre Wilson (1994) La relevancia. Comunicación y procesos cognitivos. Madrid, Visor.

Vendler, Zeno: "Verbs and Times" (1967) En Linguistics in Philosophy. Ithaca, Cornell University Press, pp. 97-121.

Verschueren, Jef (1980) On speech acts verbs. Amsterdam, John Benjamins.

Wierzbicka, Anna (1992) “The semantics of interjection”, Journal of Pragmatics, 18, pp. 159-192.

Fecha de recepción: 24 de febrero 2015

Fecha de aceptación: 30 de abril de 2015 